\title{
Effectiveness of a Brief Intervention based on Motivational Interviewing in Colombian Adolescents
}

\author{
Maria Fernanda Reyes-Rodríguez ${ }^{1}$ \\ Juliana Mejía-Trujillo \\ Augusto Pérez-Gómez \\ Francisco Cardozo \\ Catalina Pinto \\ Corporación Nuevos Rumbos
}

\begin{abstract}
Prevention science has identified evidence-based strategies for reducing alcohol and other drug use among adolescents, such as Brief Interventions (BI) and Motivational Interviewing (MI). However, there is little evidence about the effectiveness of these practices in Colombia. This study aimed to analyze the effectiveness of the preventive program Brief Intervention based on Motivational Interviewing (BIMI) in reducing alcohol use in adolescents. The program was administered to 3,159 secondary students through a within-subjects design. The results showed that BIMI is a preventive strategy that diminishes the frequency and quantity of alcohol consumption. The study examines how the elapsed time between sessions influences the results. Implications for prevention and evaluation methodologies are discussed.
\end{abstract}

Keywords. prevention, brief intervention, motivational interviewing, adolescents

\section{Efetividade de uma intervenção Breve baseada na Entrevista Motivacional com Adolescentes Colombianos}

\begin{abstract}
RESUMO - A ciência preventiva tem identificado estratégias baseadas em evidências voltadas à redução do uso de álcool e outras drogas entre adolescentes, tais como as Intervenções Breves (BI) e a Entrevista Motivacional (MI). No entanto, existe pouca evidência quanto à efetividade dessas práticas na Colômbia. Este estudo buscou analisar a eficácia do programa preventivo Intervenção Breve Baseada na Entrevista Motivacional (BIMI) em reduzir o uso de álcool em adolescentes. O programa foi conduzido junto a 3159 estudantes secundários por meio de um delineamento intra-sujeitos. Os resultados demonstraram que a BIMI constitui uma estratégia preventiva que diminui a frequência e a quantidade de uso de álcool. $\mathrm{O}$ estudo examina como o tempo transcorrido entre as sessões influencia os resultados. Implicações para a prevenção e métodos de avaliação são discutidos.
\end{abstract}

Palavras-chave: prevenção, intervenção breve, entrevista motivacional, adolescentes

The World Health Organization (WHO), in the Global Report on Alcohol and Health (2014), indicates that the harmful use of alcohol is associated with about 200 diseases, and during 2012,3.3 million deaths were attributed to alcohol use. In Colombia, WHO estimates that $8 \%$ of those over 15 years had episodes of excessive alcohol consumption in 2010 (WHO, 2014).

The national study on the use of alcohol and other drugs in school adolescents, conducted in 2011 by the Ministry of Justice and Law, Ministry of National Education and Ministry of Health and Social Protection, showed that the lifetime prevalence for alcohol was $63.4 \%$. From those who have used alcohol in the past month (39.8\%), about 5\% did so daily and $24 \%$ consumed it $1-2$ times per week. Regarding the use of other substances, the study revealed that $12 \%$ of the students have used an illicit substance at least once in their life, marijuana being the most commonly used illicit drug ( $7 \%$ lifetime prevalence). These situations, in addition to an early age of onset of drinking (12 years old) generate

1 Address for correspondence: Calle 108 A \# 4-15 Bogotá, Colombia E-mail:mfreyes@nuevosrumbos.org an increased interest in preventing the use of Psychoactive Substances (PAS) amongst adolescents.

The association between physical and social problems with alcohol use in school adolescents has been largely demonstrated (Brown, Tapert, Granholm, \& Delis, 2000; Brown \& Tapert, 2008; Medina et al., 2007; Pérez-Gómez \& Scoppetta, 2009; Pérez-Gómez, Scoppetta, \& Florez, 2010; ; Scoppetta, Pérez-Gómez, \& Lanziano, 2011; White $\&$ Swartzwelder, 2006). Thus, there is a need to develop effective strategies in reducing drug abuse, or delaying the age of onset of alcohol consumption, adapted to the school context.

The prevention of these problems makes the use of evidence-based practices necessary. In this regard, institutions such as WHO (Hawks, Scott, \& Nyanda, 2002), the National Institute on Drug Abuse (NIDA, 2003), and researchers from around the world have established and identified a number of principles to guide effective prevention practices (Becoña, 2002; Pérez-Gómez, 2003).

A response to the need for effective preventive practices is to be found in the science of prevention, which is known for its interest in the evaluation through scientific standards and 
the articulation of action research (Biglan, Wang, \& Walberg, 2003; Weissberg, Kunpfer, \& Seligman, 2003). Advances in prevention science have allowed the identification of best practices and evidence-based strategies (Fagan, Hanson, Hawkins, \& Arthur, 2008; Sloboda \& Bukoski, 2006; Wilson $\&$ Kolander, 2011) that provide a significant number of practices and effective programs such as Brief Interventions (BI) and Motivational Interviewing (MI). Nevertheless, there is little evidence of the effectiveness of these practices outside the United States, Europe and Canada.

Brief Interventions (BI) are intended for screening the problem and for the classification of the consultants at a specific level of risk. They are characterized by short sessions (15-60 minutes) and a small number of interventions (Mitchell, Gryczynski, O'Grady, \& Schwartz, 2013; O'Donnell, Wallace, \& Kaner, 2014). The BI may adopt different theoretical approaches, but in the area of substance abuse they are frequently based on motivational interviewing (MI) (Vasilaki, Hosier, and Cox, 2006).

MI is a client-centered and directive method approach, which seeks to foster intrinsic motivation and to encourage change through ambivalence management and analysis (Miller \& Rollnick, 2002). Currently, MI is considered an evidence-based strategy (Vasilaki, Hosier, \& Cox, 2006) for both adults and teenagers (Baer \& Peterson, 2002; Burke, Arkowitz, \& Menchola, 2003; Hettema, Steele, \& Miller, 2005; Lundahl, Kunz, Brownell, Tollefson, \& Burke, 2010; Rubak, Sandbaek, Lauritzen, \& Christensen, 2005), and it has been found to be effective in reducing consumption of alcohol and other drugs (Jensen et al., 2011; Pineiro, Fernández del Río, Lopez-Duran, \& Becoña, 2014).

BIs have achieved, both in undergraduate and school populations, significant reductions in substance abuse, especially alcohol, tobacco and marijuana (Babor \& Higgins, 2001; Barnett et al., 2012; Carey et al., 2007; O’Donnell et al., 2014; Salazar, Valdez, Martinez, \& Pedroza, 2010), as well as a decrease in the frequency of consumption and a reduction in the level of risk (Baer, Kivlahan, Blume, McKnight, \& Marlatt, 2001; Winters, Leitten, Wagner, \& O’Leary-Tevyaw, 2007).

The BI based on motivational interviewing as a preventive strategy has shown greater effectiveness, in terms of reduction in alcohol abuse, than other interventions (Sellman, Sullivan, Dore, Adamson, \& MacEwan, 2001; Vasilaki et al., 2006). It can have long-term benefits, even during a period of maturation (Baer et al., 2001). Notwithstanding, they are likely to be influenced by the time elapsed between sessions, and the number of sessions (Jensen et al, 2010; Lundahl et al., 2010).

Jensen et al. (2011) found that when the time intervals between MI interventions are of less than six months, there is a greater effect than in those cases with longer periods of time. For BI, Moyer, Finney, Swearingen, \& Vergun (2002) reported that the effect decreases when the time between the first intervention and the follow-up is longer. Similarly, Vasilaki et al. (2006) found that the BI based on MI were effective in all cases; however, when the follow-up is three months or less after the first intervention, its positive effects are significantly higher than when the period of time is greater.
Current evidence regarding the effectiveness and efficiency of the BI and MI is large and robust. However, the evaluation of its application in non-experimental contexts, such as school and primary care contexts remains inconsistent (O'Donnell et al. 2014). This study is aimed at analyzying the effectiveness of a prevention program proposed by the Nuevos Rumbos Corporation, referred as Brief Intervention based on Motivational Interviewing (BIMI; IBEM, acronym in Spanish), as well as to identify the impact of the period of time elapsed between the first intervention and the follow-up. The BIMI-IBEM seeks to reduce alcohol consumption among secondary school students, it is implemented individually in schools, and it uses instruments for early detection of risk.

\section{Method}

\section{Design}

A within-subjects design with one intervention and a follow-up was conducted.

\section{Participants}

This study was conducted with 3,159 students from seventh to tenth grade in 27 schools. $46 \%$ of the participants were from the central region of the country and $53 \%$ from one of the departments of the central region. Males represented $48 \%$ and females $52 \%$. The ages of the students ranged from 11 to 18 years. A follow-up was performed in a time range between one and seven months after the first session.

\section{Instruments}

CAR. This survey measures the prevalence of substance use during the past 12 months and last month. It has three items: (a) have you ever drunk alcohol? (b) have you ever smoked marijuana? (c) Have you ever used other substances that alter your mood or consciousness? When participants answered any of these questions positively, they answered also the CRAFFT / CARLOS questionnaire.

CRAFFT / CARLOS. This questionnaire developed by Knight, Goodman, Puklerwitz e DuRant (2000) is a screening tool for the detection of risk situations associated with the use of alcohol and other psychoactive substances. A modified version validated in Colombia was implemented (Scoppetta \& Pérez, 2011). The participants' level of risk for substance abuse was established through this questionnaire and the CAR tool.

The acronym CRAFFT refers to: $\mathrm{C}=\mathrm{Car}, \mathrm{R}=$ Relax; $\mathrm{A}=$ Alone, $\mathrm{F}=$ Friends, $\mathrm{F}=$ Forgetfulness, and $\mathrm{T}=$ Trouble $($ the acronym in Spanish is CARLOS). The items ask whether in the past 12 months: (a) have you ridden a car driven by someone (including yourself) who was under the influence of alcohol or drugs? (b) Have you used alcohol or drugs to relax? (c) Have you used alcohol/drugs alone? (d) Have you forgotten things you did while you were under the influence 
of alcohol or drugs? (e) Have your family or friends told you that you should drink less or use less drugs? (f) Have you had trouble under the influence of alcohol or other drugs? (Perez \& Scoppetta, 2011).

\section{Procedure}

The BIMI was delivered to all the students from 7 th to 10 th grade in the 27 schools. The BIMI seeks to reduce alcohol use or to delay the age of onset of alcohol use among secondary school students. Every student received an individual session lasting 15 minutes and a 10-15 minutes follow-up. The follow-up sought to keep in touch with the students and to determine the individual process in the compliance or non-compliance of the action plan, by identifying possible changes in alcohol use. A more extensive description of the intervention will be provided in a forthcoming paper.

First intervention. It began with a risk assessment through the CAR and CRAFFT / CARLOS questionnaire (Perez \& Scoppetta 2011). Then, the participant was placed in one of four levels of risk: low, moderate, high and severe.

The criteria to be placed in the low risk level were: (a) never having used alcohol, or no alcohol use or other substances in the past year, (b) not having had positive responses in CRAFFT / CARLOS questionnaire, or (c) having scored affirmatively in item 1: "have you ever been in a car driven by someone (which could be yourself) under the influence of alcohol or drugs?" but the person has a highrisk perception of this situation.

The moderate risk level criteria were: (a) not to having had substance use in the past year, and having a low risk perception in item one (see above), (b) having used one or more substances in the past year or past month, or (c) having two or fewer affirmative responses in the CRAFFT / CARLOS, except for items three and six.

For high-risk level the criteria were: (a) Use in the past year or last month (CAR) of one or more substances, and having answered yes to three or more items in the CRAFFT / CARLOS, or (b) having answered positively to items three and six.

Finally, the level of severe risk is defined by: (a) the student answered positively in all items of past-year use in the CAR (b) throughout the interview, a pattern of weekly or monthly use of one or more substances is identified, (3) affirmative responses to four or more items of the CRAFFT / CARLOS questionnaire.

Depending on the level of risk, the participant was invited to consider the implications of drinking by using narrative techniques. The feedback was performed using a psychoeducation strategy about the risks of using alcohol or other psychoactive substances. Thereafter, the intervention was oriented to achieve an increase in the motivation to change the pattern of consumption, by establishing an action plan with goals and strategies. The goals were focused on three groups: (a) Delaying the age at onset of using alcohol until after 18 or even 21 years old, (b). Reduce the frequency and / or quantity of use of alcohol and other substances, and (c) maintain no use of alcohol and other substances (both those who wanted to stay in zero use as well as those planning to stop using).

Follow up. For the present study the follow-ups were conducted at different periods of time. In some schools, the follow-ups were carried out one to three months after the first intervention ( $n=2465)$, while in others that happened between three and seven months $(\mathrm{n}=694)$. The follow-up consisted in inquiring if the participant had used any substance after the first intervention and during the month prior to the follow-up. Following this, the student was classified in a new level of risk, based on the accomplishment of the goal. Facilitators, challenges and the most effective strategies were also explored.

\section{Ethical Considerations}

An informed consent was provided by the educational institution, to which participants were linked, and assent from the students was obtained. These consent and assent explained that participation in the intervention was entirely voluntary and confidential. Moreover, participants were informed that nothing related to their identity would be revealed, and that they had the right to withdraw from the intervention at any time. The cases of severe risk were referred to the mental health professional authorized within the school to receive the necessary attention; this was also included in the student's consent.

\section{Results}

BIMI was evaluated based on three indicators: (a) changes in alcohol use prevalence in the last month, (b) changes in the level of risk; and (c) the achievement of goals.

\section{Changes in Alcohol Use: Comparison of Last Month Prevalence and Goal Achievement}

At the moment of the first intervention, a prevalence of alcohol use of $44 \%$ was found for the last month ( $42 \%$ male and $45 \%$ female). It should be emphasized that no significant differences in the prevalence of consumption were found according to gender. Regarding the fulfillment of the goals, it was found that $68 \%$ of the participants achieved the goal, $19 \%$ partially achieved them and $13 \%$ did not fulfill them.

When prevalence of alcohol consumption in the last month in the first intervention and follow up were compared, a significant decrease $\left(\chi^{2} \mathrm{McNemar}=90.89, p<0.001\right)$ for the total sample (see Figure 1) was found. This significant decrease in alcohol use in the last month after the intervention was found in both men and women $\left(\chi^{2}\right.$ McNemar $=39.02, p$ $<0.001$ ) (see Figure 1).

A reduction of $54 \%$ was found in students who consumed alcohol in the last month. Among those who had not used in the past 30 days, $77 \%$ maintained a non-consumption, and $23.5 \%$ reported consumption within the past month before the follow-up. 


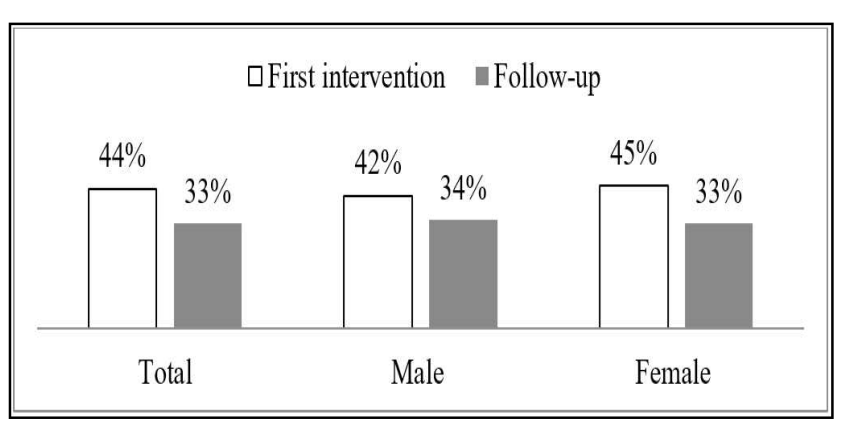

Figure 1. Prevalence of alcohol use in the last month before and after the intervention by total sample and gender

An analysis for each community was performed to identify changes in the prevalence in each site where the intervention was implemented. As shown in Table 1, there was a significant decrease in the prevalence of alcohol use for five of the eight communities. It was observed, however, that in three communities there was no significant reduction, but in all cases these corresponded to communities where the time elapsed between the intervention and the follow up was longer.

This research also aimed to identify whether the time between the first intervention and follow-up influenced the results of the intervention. For this reason, the schools were grouped according to the time between sessions, as follows: (a) Group A: period of time of one to three months between first session and follow-up, and (b) Group B: period of time longer than three months.

To identify differences between the two conditions of time, an analysis of independent measures was conducted, using as dependent variable the compliance of the goal. The results revealed significant differences between the two

Table 1. Comparison of prevalence of alcohol consumption in the last month per community, before and after the intervention

\begin{tabular}{ccc}
\hline \multirow{2}{*}{ Community } & \multicolumn{2}{c}{ Alcohol use in the past month } \\
\cline { 2 - 3 } & First intervention & Follow-up \\
\hline C1 $^{\text {ab }}$ & $34 \%$ & $36 \%$ \\
C2 $^{\mathbf{b}}$ & $50 \%$ & $52 \%$ \\
C3 $^{\mathbf{a}}$ & $46 \%$ & $30 \% * *$ \\
C4 $^{\mathbf{a}}$ & $58 \%$ & $25 \% * *$ \\
C5 $^{\mathbf{a}}$ & $37 \%$ & $36 \%$ \\
C6 $^{\mathbf{a}}$ & $54 \%$ & $27 \% * *$ \\
C7 $^{\mathbf{a}}$ & $47 \%$ & $26 \% * *$ \\
C8 $^{\mathbf{a}}$ & $51 \%$ & $29 \% * *$ \\
\hline
\end{tabular}

Note. The McNemar test was used to calculate differences. ${ }^{* *} p<.001$. a) Communities with schools where the time elapsed between the first intervention and the follow-up were from one to three months; $b$ ) Communities with schools with time elapsed between first intervention and follow-up was longer than three months. conditions $(\chi 2(2)=19.94, p<0.001)$. Group A (less than three months) met the goal in a significantly higher proportion than group B ( $70 \%$ and $64 \%$, respectively).

When comparing the prevalence of alcohol use in the past month in the first intervention and the follow up by time condition, significant differences were also found. Group A had a smaller proportion of alcohol use than group B (Table 2).

\section{Risk Level}

Another outcome indicator refers to changes in the level of risk. A Friedman test was performed to identify significant changes. A significant decrease in the level of risk $\left(\chi^{2}(1)=\right.$ 876.36, $p<0.001)$ was observed after the first intervention (average ranges First Int. $=1.7$, average ranges of follow-ups $=1.3$ ). As shown in Table 3, the proportion of students in the low-risk level increased in the follow-up, and the moderate, high and severe levels decreased.

In addition, we investigated changes in the prevalence of alcohol use according to the initial level of risk. Significant changes for all levels of risk were found. However, in the group categorized during the first intervention as low risk, the prevalence of alcohol consumption increased in the last month at follow-up (see Table 4).

\section{Discussion}

The results of this study show that the program BIMI works as a preventive strategy for secondary school students from 7 th to 10th grade in Colombia, insofar as it contributes to the decrease in the frequency and quantity of alcohol use. However, the effects were observed in the groups where the follow-up was implemented between one to three months after the first intervention, and not in those groups where the follow up exceeded three months. These results are similar to those found elsewhere (e.g., Jensen et al., 2011; Lundahl et al., 2010; Moyer et al., 2002; Vasilaki et al., 2006).

To establish the success of the program, the changes in patterns of alcohol consumption (last month prevalence) and the changes in level of risk and compliance of self-proposed goals regarding consumption were assessed. Usually, the latter, that is, the reduction or total rejection of alcohol intake, is closely related to positive changes in consumption patterns, but it's not necessarily linked to changes in risk level: many students formulated as a goal to stop consumption, but many others looked only for a reduction which not necessarily produced a change in the level of risk.

The prevalence increased significantly in students who were categorized in a low level of risk in the first intervention. Many factors can influence this result, such as age (the

Table 2. Comparison of prevalence of alcohol use in the last month by time condition before and after the intervention

\begin{tabular}{lcc}
\hline Time between first session and Follow-up & Alcohol Last month 1st intervention & Alcohol last month follow-up \\
\hline 1 to 3 months & $45 \%$ & $32 \% \%^{* *}$ \\
Longer than 3 months & $38 \%$ & $37 \%$ \\
\hline Note: ${ }^{* *} p<0.001$ & &
\end{tabular}


Table 3. Risk levels compared before and after the BIMI intervention

\begin{tabular}{|c|c|c|c|c|}
\hline Risk Level & Low & Moderate & High & Severe \\
\hline First Intervention & $29 \%$ & $53 \%$ & $16 \%$ & $2 \%$ \\
\hline Follow-up & $58 \%$ & $33 \%$ & $9 \%$ & $1 \%$ \\
\hline
\end{tabular}

Table 4. Prevalence of alcohol use in the last month before and after the intervention for risk level

\begin{tabular}{lcc}
\hline \multirow{2}{*}{ Risk Level } & Alcohol use last month first intervention & Alcohol use last month Follow-up \\
\cline { 2 - 3 } & YES & YES \\
\hline Low* & $0 \%$ & $15.1 \%$ \\
Moderate* & $53.5 \%$ & $37.2 \%$ \\
High* & $77.4 \%$ & $49.5 \%$ \\
Severe* & $87.0 \%$ & $44.2 \%$ \\
\hline Note:**p<0.001 & &
\end{tabular}

Note: $* * p<0.001$

average age was 14 years), the specific situations of the life span (for example increased attendance to parties), or variables unrelated to the subject of the study. At other risk levels (Medium, High and Severe), the prevalence decreased significantly.

Notwithstanding, BIMI's results can disappear quickly if they are not strengthened by other actions that support adolescents in the maintenance of positive behavior, such as the development of individual abilities, as well as activities and actions with family members and teachers. Moreover, a specific intervention aimed at decreasing the risk factors to which adolescents are exposed in the family, the school, the community, or with their own peers may be beneficial.

The interaction with the adolescents during the BIMI hints at what might be the main themes of work with them and what are the most effective strategies in achieving a reduction in alcohol consumption. These are focused on assertiveness to handle situations that require their decision and firmness to try to avoid contact with users and conduct other type of activities, such as sports, recreational or cultural.

Although the present study lacks a control group allowing to ensure that the positive results observed were due to BIMI, our within subjects design helps to control potential bias. Nevertheless, it is important to perform further studies that include a control group, as well as having diverse time conditions between the intervention and the follow-up, to maximize the potential positive results of the intervention.

It is important to develop similar projects with school drop-out adolescents; the follow-up reached approximately $75 \%$ of those who participated in the first session, and this was largely due to school desertion, and to a lesser extent to changes of school. Adolescents who drop out of school do so primarily for starting their working life (sometimes forced by their parents' difficult economic situation); this produces an increased risk, because the availability of money can facilitate the acquisition of alcohol.

Currently NRC is developing a second follow-up, to be carried out three months after the first one, which would include three family meetings. In this way, NRC will be able to measure more precisely the effectiveness of the program, on the basis of a diversity of designs founded on various criteria, as follows: time elapsed between interventions; number of interventions; and kind of interventions. So far,
BIMI seems to reduce or delay the age of onset of alcohol use in Colombian adolescents aged 12 to 17 years old, when follow-up does not exceed three months after the first intervention.

\section{References}

Babor T. F., \& Higgins-Biddle J. C. (2001). Brief intervention for hazardous and harmful drinking: A manual for use in primary care. World Health Organization. Department of Mental Health and Substance Dependence. Retrieved from http://whqlibdoc. who.int/hq/2001/who_msd_msb_01.6b.pdf

Baer J., Kivlahan, D. R., Blume, A. W., McKnight, P., \& Marlatt, G. A. (2001). Brief intervention for heavy-drinking college students: 4-year follow-up and natural history. American Journal of Public Health, 91(8), 1310-1316.

Baer, J., \& Peterson, P. (2002). Motivational interviewing with adolescents and young adults. In W. Miller \& S. Rollnick (Eds), Motivational Interviewing: Preparing people to change (pp. 320-332). New York, New York: The Guilford Press.

Barnett, E., Sussman, S., Smith, C., Rohrbach, L. A, \& Spruijt-Metz, D. (2012). Motivational Interviewing for adolescent substance use: a review of the literature. Addictive Behaviors, 37(12), 1325-34. doi: 10.1016/j.addbeh.2012.07.001

Becoña, E. (2002). Bases científicas de la prevención de las drogodependencias. Plan nacional sobre drogas. Madrid: Imprenta Nacional del Boletín Oficial del Estado.

Biglan, A., Wang, M. C., \& Walberg, H.J. (2003) Preventing youth problems. New York: Kluwer Academic/Plenum.

Brown, S. A. \& Tapert, S.F. (2008). Adolescence and the trajectory of alcohol use: Basic to clinical studies. Annals of the New York Academy of Sciences, 1021, 232-244.

Brown, S. A., Tapert, S. F., Granholm, E., \& Delis, D. C. (2000). Neurocognitive functioning of adolescents: Effects of protracted alcohol use. Alcoholism, Clinical and Experimental Research, 24(2),164-71.

Burke, B. L., Arkowitz, H., \& Menchola, M. (2003). The efficacy of motivational interviewing: A meta-analysis of controlled clinical trials. Journal of Consulting and Clinical Psychology, 71, 843-861. doi: 10.1037/0022-006X.71.5.843 
Carey, K. B., Scott-Sheldon, L. A., Carey, M. P., \& DeMartini, K. S. (2007). Individual level interventions to reduce college student drinking: A meta-analytic review. Addictive Behaviors, 32, 2469-2494.

Fagan, A., Hanson, K., Hawkins, D., \& Arthur, M. (2008). Bridging science to practice: achieving prevention program implementation fidelity in the Community Youth Development Study. American Journal of Community Psychology, 41, 235249. doi: 10.1007/s10464-008-9176-x.

Hawks, D., Scott, K., \& McBride, N. (2002). Prevention of psychoactive substance use: A selected review of what works in the area of prevention. Geneva: World Health Organization.

Hettema, J., Steele, J., \& Miller, W. R. (2005). Motivational interviewing. Annual Review of Clinical Psychology, 1, 91-111. doi: 10.1146/annurev.clinpsy.1. 102803.143833

Knight, J. R., Goodman, E., Puklerwitz, T., \& DuRant, R. (2000). Reliabilities of Short Substance Abuse Screening Test among adolescent medical patients. Pediatrics, 105(4), 948-953.

Jensen, C., Cushing, C., Aylward, B., Craig, J., Sorell, D., \& Steele, R. (2011). Effectiveness of motivational interviewing interventions for adolescent substance use behavior change: A meta-analytic review. Journal of Consulting and Clinical Psychology, 79(4), 443-440. doi: 10.1037/a0023992.

Lundahl, B., Kunz, C., Brownell, C., Tollefson, D., \& Burke, B. (2010). A meta-analysis of Motivational Interviewing: Twentyfive years of empirical studies. Research on Social Work Practice, 20(2), 137-160. doi: 10.1177/1049731 509347850.

Miller, W. R., \& Rollnick, S. (2002). Motivational interviewing: Preparing people for change (2nd ed.). Nueva York: Guildford Press.

Mitchell, S. G., Gryczynski, J., O'Grady, K. E., \& Schwartz, R. P. (2013). SBIRT for adolescent drug and alcohol use: Current status and future directions. Journal of Substance Abuse Treatment, 44(5), 463-72.

Medina, K. L., Hanson, K. L., Schweinsburg, A. D., Cohen-Zion, M., Nagel, B. J., \& Tapert, S. F. (2007) Neuropsychological functioning in adolescent marijuana users: Subtle deficits detectable after a month of abstinence. Journal of International Neuropsychology Society, 13(5), 807-20.

Ministry of Justice and Law, Ministry of National Education and Ministry of Health and Social Protection [Ministerio de Justicia y del Derecho, Ministerio de Educación Nacional, y Ministerio de Salud y Protección Social]. (2011). Estudio nacional de consumo de sustancias psicoactivas en población escolar. Retrieved from: http://www.unodc.org/documents/colombia/ Documentostecnicos/Estudio_Consumo_Escolares.pdf

Moyer, A., Finney, J., Swearingen, C., \& Vergun, P. (2002). Brief interventions for alcohol problems: A meta-analytic review of controlled investigations in treatment-seeking and nontreatment seeking populations. Addiction, 97, 279-292.

National Institute on Drug Abuse. (2003). Preventing drug use among children and adolescents: A research-based guide for parents, educators, and community leaders. Retrieved from http://www.drugabuse.gov/sites/default/files/ preventingdruguse_2.pdf
O'Donell, A., Wallace, P., \& Kaner, E. (2014). From efficacy to effectiveness and beyond: What next for brief interventions in primary care? Frontiers in Psychiatry, 5(113), 1-8. doi: $10.3389 /$ fpsyt.2014.00113

Pérez-Gómez, A. (2003). El impacto del consumo de drogas en el mundo y en el campo preventivo: ¿Qué funciona en el campo preventivo? Revista Peruana de Drogodependencias, 1(1), 195-208.

Pérez, A., \& Scoppetta, O. (2009). Consumo de alcohol en menores de 18 años en Colombia 2008: Estudio en 7 capitales y dos municipios pequeños. Bogotá: Nuevos Rumbos/Dupligráficas.

Pérez-Gómez, A., \& Scoppetta Díaz-Granados, O. (2011). El CRAFFT/CARLOS como instrumento para la identificación temprana de consumo de alcohol y otras SPA: Una adaptación al Español. Revista Colombiana de Psicología, 20(2), 265-274.

Pérez-Gómez, A., Scoppetta, O., \& Flórez-Alarcón, L. (2010). Age at onset of alcohol consumption and risk of problematic alcohol and psychoactive substance use in adulthood un general population in Colombia. The Journal of International Drug, Alchol and Tobacco Research, 1(1), 19-24.

Piñeiro B., Fernández del Río E., López-Durán A., \& Becoña E. (2014) ¿Mejora la entrevista motivacional la eficacia del tratamiento psicológico para dejar de fumar? Anales de Psicología, 30, 123-132.

Rubak, S., Sandbaek, A., Lauritzen, T., \& Christensen, B. (2005). Motivational interviewing: A systematic review and metaanalysis. British Journal of General Practice, 55, 305-312.

Salazar de Garza, M. L., Valdez-Ruiz, J. F., Martínez-Martínez, K. I., \& Pedroza-Cabrera, F. J. (2010). Intervenciones breves con adolescentes estudiantes rurales que consumen alcohol en exceso. Universitas Psychologica, 10(3), 803-815.

Sellman, J. D., Sullivan, P. F., Dore, G. M., Adamson, S. J., \& MacEwan, I. (2001). A randomized controlled trial of motivational enhancement therapy (MET) for mild to moderate alcohol dependence. Journal of Studies on Alcohol and Drugs, 62(3), 389

Slobda, Z., \& Bukoski, W. (2006). Handbook of drug abuse prevention: Theory, science and practice. New Tork, NY: Springer.

Scoppetta, O., Pérez, A., \& Lanziano, C. (2011). Perfiles asociados al consumo de alcohol de adolescentes escolarizados mediante análisis de correspondencias múltiples. Acta Colombiana de Psicología, 14(1), 139-146.

Vasilaki, E., Hosier, S., \& Cox, M. (2006). The efficacy of Motivational Interviewing as a brief intervention for excessive drinking: A meta-analytic review. Alcohol \& Alcoholism, 41(3), 328-335. doi: 10.1093/alcalc/ag1016.

Weissberg, R. P., Kumpfer, K. L., \& Seligman, M. E. P. (2003). Prevention that works for children and youth: An introduction. American Psychologist, 58(6/7) 425-432.

White, A. M., \& Swartzwelder, H. S. (2006). Age-related effects of alcohol on memory and memory-related brain functions in adolescents and adults. In M.Galanter (Eds.), Recent developments in alcoholism (vol. 17, pp. 167-176). New York, NY: Springer. 
Wilson, R., \& Kolander, C. A. (2011). Drug abuse prevention: A school and community partnership. Sudbury, MA: Jones and Bartlett Publishers.

Winters, K. C., Leitten, W., Wagner, E., \& O'Leary Tevyaw, T. (2007). Use of brief interventions in a middle and high school setting. Journal of School Health, 77, 196-206.
World Health Organization [Organización Mundial de la Salud]. (2014). Global status report on alcohol and health. Retrieved from http://apps.who.int/iris/bitstream/10665/112736/1/ 9789240692763_eng.pdf.

Recebido em 13.01.2015

Primeira decisão editorial em 01.09.2015

Aceito em 01.09.2015 